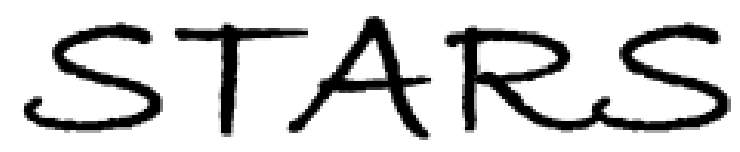

University of Central Florida

STARS

$1-1-2009$

\title{
Urban land use and land cover classification using the neural- fuzzy inference approach with Formosat-2 data
}

Ho-Wen Chen

Ni-Bin Chang

University of Central Florida

Ruey-Fang Yu

Yi-Wen Huang

Find similar works at: https://stars.library.ucf.edu/facultybib2000

University of Central Florida Libraries http://library.ucf.edu

This Article is brought to you for free and open access by the Faculty Bibliography at STARS. It has been accepted for inclusion in Faculty Bibliography 2000s by an authorized administrator of STARS. For more information, please contact STARS@ucf.edu.

\section{Recommended Citation}

Chen, Ho-Wen; Chang, Ni-Bin; Yu, Ruey-Fang; and Huang, Yi-Wen, "Urban land use and land cover classification using the neural-fuzzy inference approach with Formosat-2 data" (2009). Faculty Bibliography 2000s. 1412.

https://stars.library.ucf.edu/facultybib2000/1412

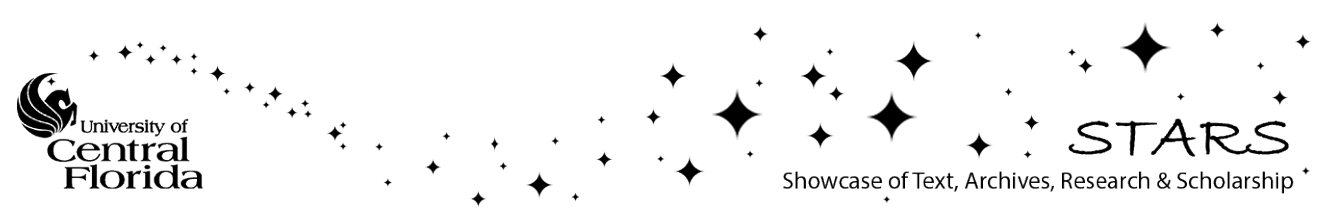




\title{
Urban land use and land cover classification using the neural-fuzzy inference approach with Formosat-2 data
}

\author{
Ho-Wen Chen, ${ }^{a}$ Ni-Bin Chang, ${ }^{b}$ Ruey-Fang Yu, ${ }^{c}$ Yi-Wen Huanga \\ ${ }^{a}$ Department of Environmental Engineering and Management, \\ Chao-Yang University of Technology, Taichung, Taiwan \\ hwchen@cyut.edu.tw and_88825026@hotmail.com \\ ${ }^{\mathrm{b}}$ Department of Civil, Environmental, and Construction Engineering, \\ University of Central Florida, Orlando, Florida, USA \\ nchang@mail.ucf.edu \\ ${ }^{\mathrm{c}}$ Department of Safety, Health and Environmental Engineering, \\ National United University, Miao-Li, Taiwan \\ rfyu@,nuu.edu.tw
}

\begin{abstract}
This paper presents a neural-fuzzy inference approach to identify the land use and land cover (LULC) patterns in a fast growing urban region with the 8-meter resolution of multi-spectral images collected by Formosat- 2 satellite. Texture and feature analyses support the retrieval of fuzzy rules in the context of data mining to discern the embedded LULC patterns via a neural-fuzzy inference approach. The case study for Taichung City in central Taiwan shows the application potential based on five LULC classes. With the aid of integrated fuzzy rules and a neural network model, the optimal weights associated with these achievable rules can be determined with phenomenological and theoretical implications. Through appropriate model training and validation stages with respect to a groundtruth data set, research findings clearly indicate that the proposed remote sensing technique can structure an improved screening and sequencing procedure when selecting rules for LULC classification. There is no limitation of using broad spectral bands for category separation by this method, such as the ability to reliably separate only a few (4-5) classes. This normalized difference vegetation index (NDVI)-based data mining technique has shown potential for LULC pattern recognition in different regions, and is not restricted to this sensor, location or date.
\end{abstract}

Keywords: Formosat-2, land use classification, neural network, fuzzy inference, data mining

\section{INTRODUCTION}

Urban areas are characterized by a large variety of built-up environments and natural vegetation cover which not only determine the surface features of a city, such as land use patterns, but also influence ecological, climatic and energetic conditions of land surface processes. Information about land use and land cover (LULC) patterns in urban regions is often required for meeting the needs of urban planning and environmental management. Since remote sensing is capable of capturing temporal and spatial data, it has been applied to various environmental sensing and monitoring problems such as land cover, forest structure, species composition, land development conditions, heat island effects [1], and carbon storage [2]. To monitor the land use dynamics in a city, developing an innovative data mining technique with respect to both space- and air-borne data for cost-effective LULC identification has become an important topic in sustainable urban development with digital city implications [3]. 
To capture and interpret the features embedded in the surface of an observed object, a profound knowledge of image characteristics and highly developed technologies are required [4-6]. Many experiments based on spatial, spectral, and textural analyses were carried out to generate land cover maps to support land development and conservation efforts [7-12]. The applicability of remote sensing in solving environmental issues such as environmental change, environmental monitoring [13], disaster prevention [14], and climate prediction [15] has been well established. Image classification is often the basic step in such advanced applications. The concept of image classification is often implemented based on the fact that the spectral signature of each pixel contains information on the physical characteristics of the observed materials underlying the pixel. By analyzing such information from satellite images we can infer the type of materials associated with that pixel. However, the major problem is that spectral non-homogeneity within a particular type of material or land cover makes the classification of land cover difficult [16]. For this reason many methodologies originating from statistics and evolutionary computation have been proposed to improve the accuracy of the classification [17-20]. Thus, numerous rules and bodies of experience, either involving objective reality or subjective cognizance, about land use classification have been established [18-20]. Constructing a knowledge base to integrate this experience is a matter of concern not only for knowledge acquisition but also for advanced applications of remote sensing.

Fuzzy inference, a 'computational intelligence (CI)' technique that is a branch of artificial intelligence, is capable of incorporating experts' knowledge and available measurements for a system with a set of easily comprehensible rules [21]. Both quantitative and qualitative expressions can be comprehensively addressed in fuzzy inference models. This approach has shown great potential in simulation, prediction and control, especially when analytical approaches fail mainly due to increased mathematical complexity. The primary drawback of fuzzy rule-based systems is the absence of precise algorithms for delineating fuzzy membership functions and identifying the fuzzy rules that govern a system. Artificial Neural Networks (ANNs) are data-driven models with high fault-tolerance which have the ability to learn, recall, generalize and adapt with the aid of training data sets. To integrate and synthesize the advantages of both neural networks and fuzzy rule-based systems, fuzzy neural network (FNN) models were proposed to deal with human-like reasoning with expert knowledge [22-24]. Because the accuracy and applicability of fuzzy inference depends on the contents of a rule base, how to build a set of expert rules becomes the key point for most FNN systems $[25,26]$.

As the experts' experiences are the main source for building rule bases, researchers have proposed various methodologies to extract expert knowledge efficiently [25, 26]. However, some regular patterns hidden in natural systems, especially in urban environments, are usually ignored because they are easily concealed under the complexity of recognized systems. It might be possible to gain further insight if both texture and feature analyses could be combined with each other to help retrieve the fuzzy rule-base supported by a unique neural network to optimally extract an appropriate subset of rules to support LULC classification. Therefore, this paper aims to develop such a data mining approach in a highly developed urban region to discern both obvious and hidden LULC patterns.

\section{METHODOLOGY}

\subsection{Study area}

Taichung City, located in central Taiwan, is a rapidly growing urban area. It consists of eight districts with a total area of $163 \mathrm{~km}^{2}$ (Fig. 1). At present, there are about one million residents in this city, and most people reside in the downtown districts. High population density and limited land resources have allowed no other choice but to dissect the available land surface into small pieces for various usages. Having been rapidly expanding since 1986, versatile 
LULC patterns make regular inventory of the land resources into a time consuming and exhaustive activity. Local decision makers and stakeholders require an efficient tool to monitor the land use dynamics for advanced urban and regional planning as well as environmental management. However, fragmental land usages increase the complexity of LULC classification city wide, especially in the downtown area. In order to improve the accuracy of a LULC classification, this study employs the normalized difference vegetation index (NDVI) - a remote sensing technique applied to the satellite images acquired from the Formosat-2 multispectral sensor with a resolution of $8 \mathrm{~m}$ and a daily repeat cycle. The proposed FNN model below may uniquely support the efficient LULC classification for any similar land management task.

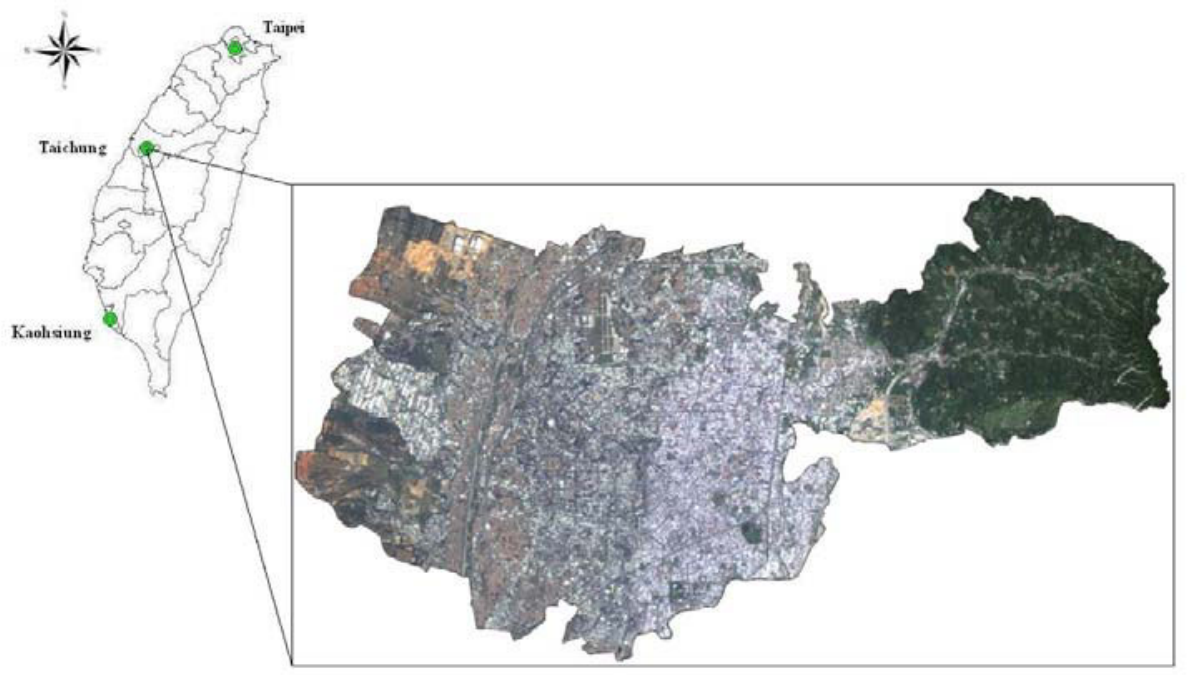

Fig. 1. The location of the study area and its LULC aerial image

\subsection{Data requirements}

Formosat-2, Taiwan's own first satellite for environmental remote sensing, was launched on May $21^{\text {st }}, 2004$. It is a sun-synchronous satellite traveling in a fixed orbit $891 \mathrm{~km}$ above the ground, and it circles the Earth 14 times each day. Its technical features are listed in Table 1. During daytime, Formosat- 2 can be used for land use identification, natural resources management, environmental protection, and disaster prevention. To identify the patterns of LULC, an image taken by Formosat-2 has a swath width of $24 \mathrm{~km}$, a panchromatic (black/white) resolution of $2 \mathrm{~m}$ and a multi-spectral (color) of $8 \mathrm{~m}$. Thus, Formosat-2's $8 \mathrm{~m}$ multi-spectral satellite images covering the whole Taichung City were used for this analysis. The image was taken in September of 2005, with the range between latitudes N24 ${ }^{\circ} 13$ '23' to $\mathrm{N} 24^{\circ} 6^{\prime} 20^{\prime \prime}$ and between longitudes E120 $0^{\prime} 3^{\prime} 57^{\prime \prime}$ to E120 $33^{\prime} 58^{\prime \prime}$. For the LULC classification, the red, blue, green and near-infrared wavelength bands were used for the purpose of developing the rules inherent in the images. The total number of raster pixels in the study area is $1711 \times 2924$. 
Table 1. The features of Formosat-2 satellite

\begin{tabular}{|c|c|c|}
\hline Satellite Parameter & Panchromatic & Multi-Spectral \\
\hline Ground Resolution & $2 \mathrm{~m}$ & $8 \mathrm{~m}$ \\
\hline Numbers of Bands & 1 & 4 \\
\hline Wavelengths/ & & $\begin{array}{l}\text { Blue band (B): } 0.45 \sim 0.52 \mu \mathrm{m} \\
\text { Green band }(\mathrm{G}): 0.52 \sim 0.60 \mu \mathrm{m} \\
\text { Red band (R): } 0.63 \sim 0.69 \mu \mathrm{m} \\
\text { Near infrared band (NIR): } \\
0.76 \sim 0.9 \mu \mathrm{m}\end{array}$ \\
\hline Satellite angular range & front/back $45^{\circ} ;$ side $45^{\circ}$ & \begin{tabular}{c} 
front $/$ back $45^{\circ} ;$ side $45^{\circ}$ \\
\hline Image width
\end{tabular} \\
\hline
\end{tabular}

\subsection{Training data selection}

The Fuzzy reasoning approach, which is capable of conceptually representing the vagueness of natural languages by using fuzzy numbers, was applied in this paper to incorporate expert knowledge for the classification of objects on urban surfaces with a set of comprehensible rules. Because of their abilities to learn, recall, generalize and adapt based on the training data sets, ANNs were applied in this study to help delineate fuzzy membership functions and identify the fuzzy rules which govern a system. Fig. 2 shows the systematic flowchart of this approach consisting of six steps: (1) collection of samples or training data for each land use class; (2) image pretreatment for computation of features and textures that can discriminate among classes via the data mining approach; (3) generation of a fuzzy rule base; (4) determination of the optimal weights associated with rules in the rule base by using ANNs; (5) execution of accuracy analysis; and (6) interactive refinement of the rule base. To ensure that only one definite land type was defined when capturing the features associated with various LULC patterns, a set of patches corresponding to grass ground, bare field, buildings, road and river were sampled by manual selection.

As deviation from a specific land type may produce a gentle degradation in the rule firing strength and even result in a wrong solution, box plots was used to screen out the statistical outliers. Simultaneously, transformed divergence [27] was also applied to remove the samples which were not well-separated from other land types. If poor discrimination did not originate from the training data sets but from the unsuitable classification rules, the procedure for creating new training data sets may be abandoned and the finding may be considered as a redundant rule. Therefore, homogenous training data sets for seeding classification rules can be objectively identified. After the series of procedures described above, together with a terrain exercise, a total of 207 samples with 55,144 pixels were selected as training data sets for the study area.

\subsection{Fuzzy rules generation using a data mining approach}

The core of fuzzy reasoning is its content comprised of fuzzy "if-then" rules. Because the quality of rules can determine the accuracy and applicability of the inference model, how to extract and prune the rules is the key point in developing a fuzzy inference model. To characterize the features endowed with various land covers in satellite images, a data mining approach was taken. Based on the results of data mining, fuzzy numbers were processed to describe the ambiguity in determining categories of land usage types. The complete methodology can be further illustrated as follows. 


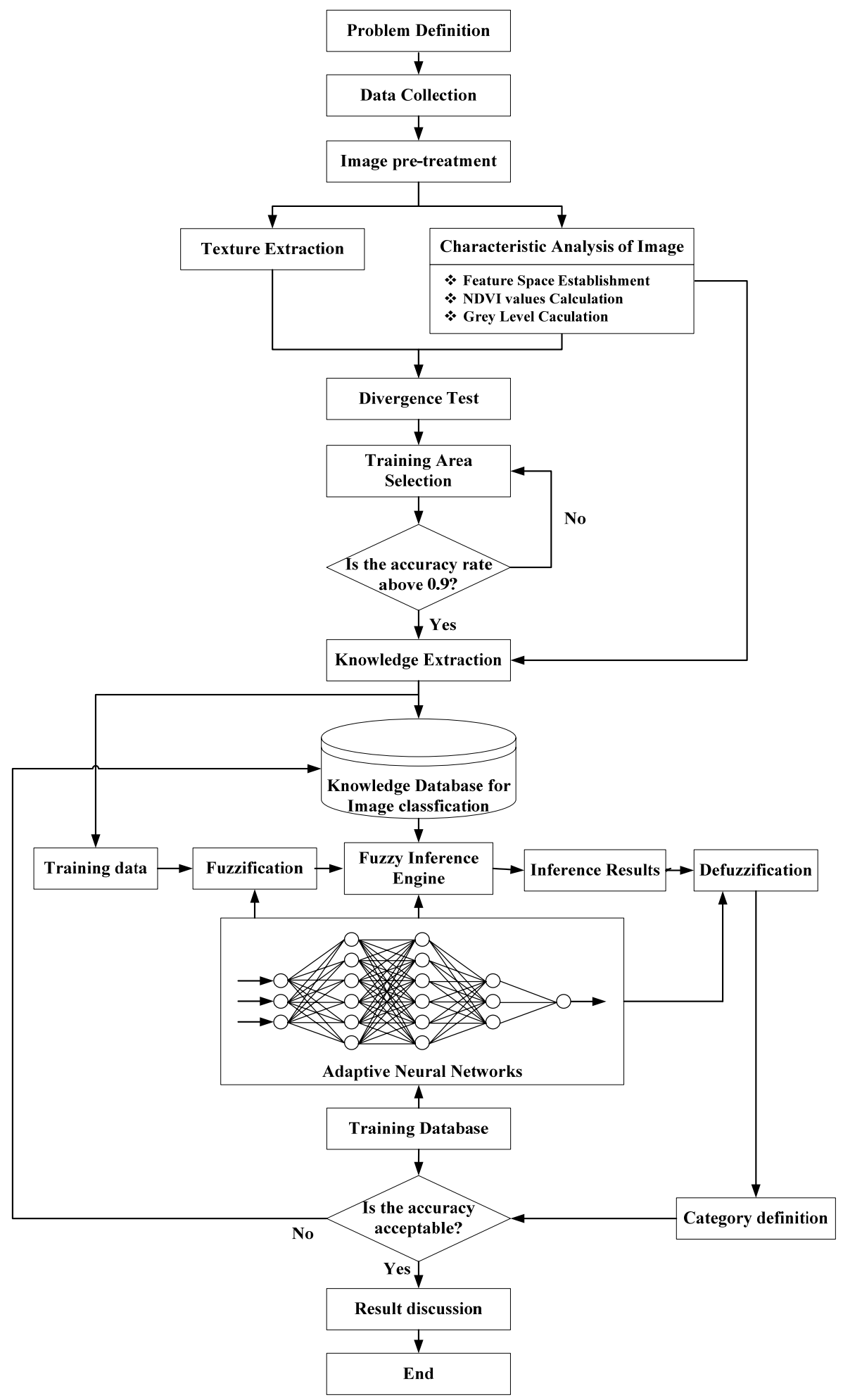

Fig. 2. The flowchart of the neural-fuzzy inference approach to LULC mapping. 


\subsubsection{Basic statistical characteristics}

Four types of training data sets were used to determine the possibility distributions of wavelength for the purpose of scripting the responding box plots. As shown in Fig. 3, over 600 groundtruth data points were collected to summarize the statistical box plots for each land use type with respect to each band. Given these characteristics, as shown in Fig. 4 some fuzzy membership functions were established to identify the relationships between spectra and land covers. The horizontal axis represents the intensity of radiation that actually reaches the satellite sensor expressed in digital numbers (DNs), which can be translated into at-satellite radiances using sensor and band-specific coefficients, and range from $0-255$ for 8 bit images; in this case, higher DN values correspond to greater brightness. Both Fig. 4 and Fig. 5 collectively indicate that this neural network-based fuzzy reasoning system may be more beneficial than using triangle membership functions to smooth out the data mining process. Following these results, the fuzzy rules for LULC classification were summarized in Table 2.

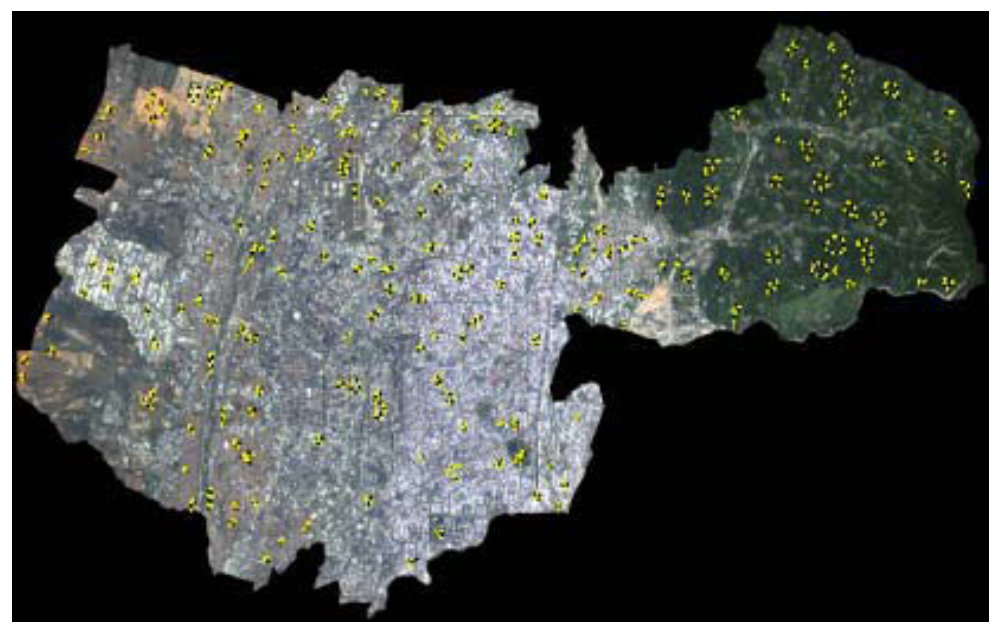

Fig. 3. Distribution of groundtruth data points in the study area.
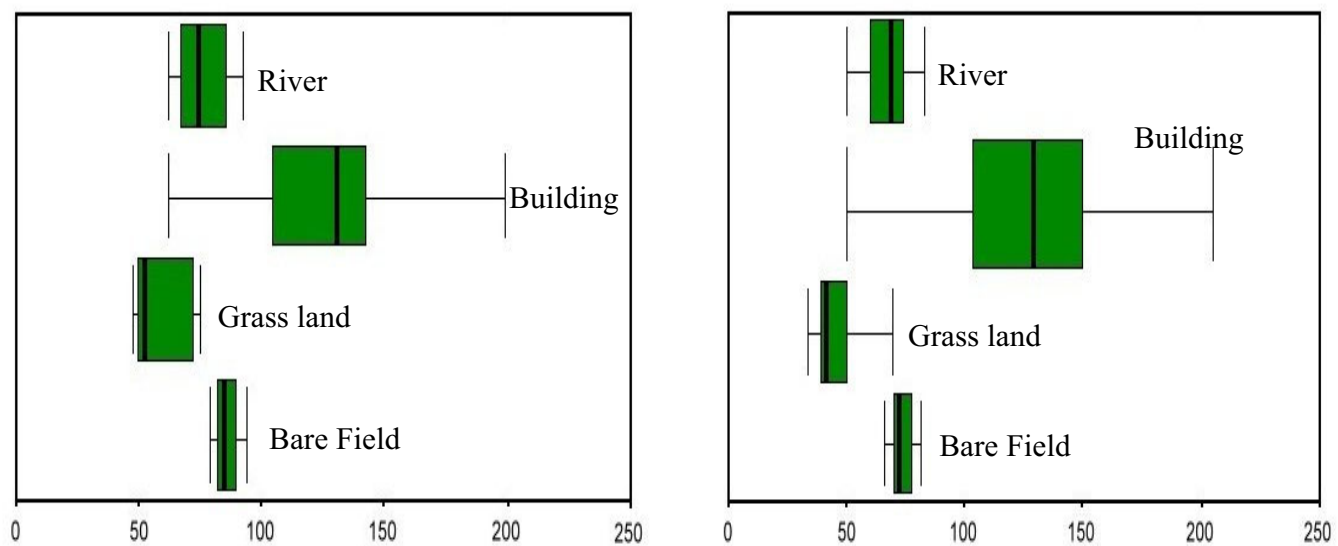


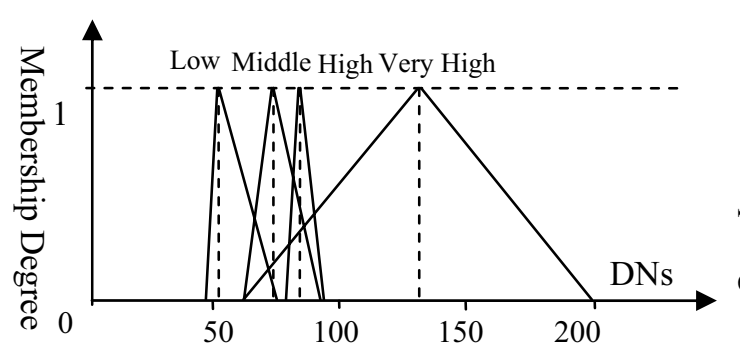

(A) Blue Band

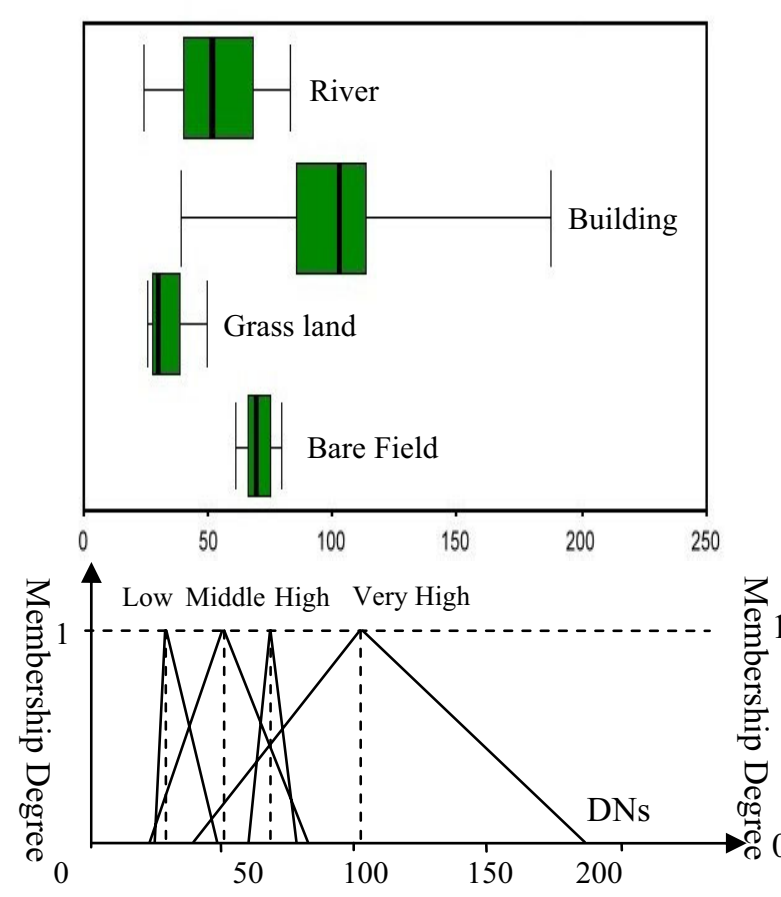

(C) Red Band

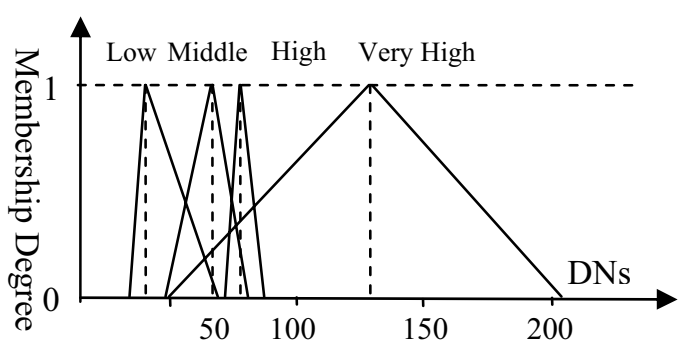

(B) Green Band

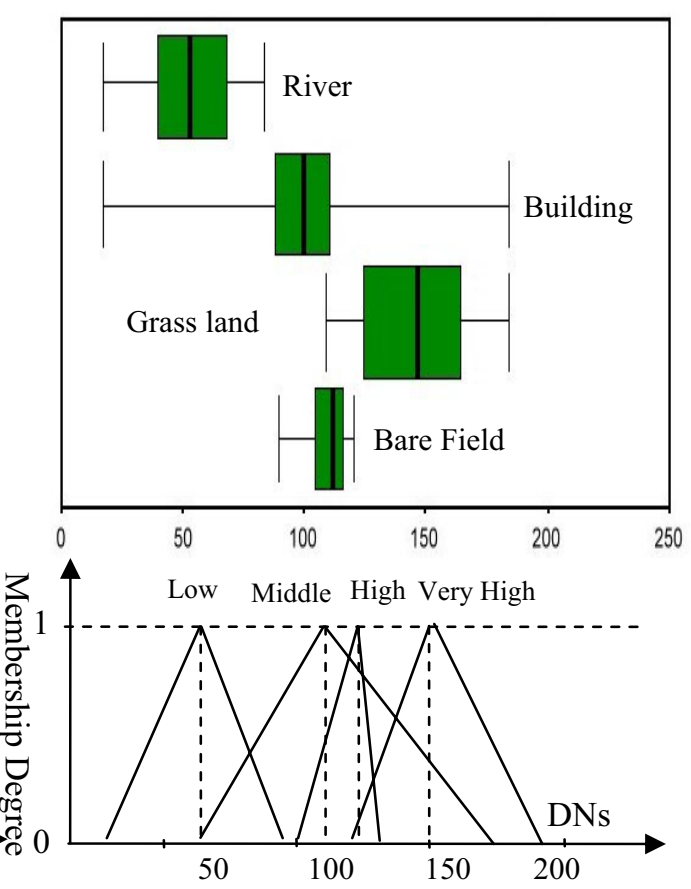

(D) Near infrared Band

Fig. 4. DN distributions of various LULC types and corresponding membership functions.

Table 2. Fuzzy rules generated from the statistical characteristics of sensor bands

\begin{tabular}{|c|l|l|}
\hline Rule no. & \multicolumn{1}{|c|}{ If } & \multicolumn{1}{c|}{ Then } \\
\hline 1 & $\mathrm{~B}, \mathrm{G}$, or $\mathrm{R}$ is $\mathrm{M}$ or NIR is $\mathrm{L}$ & River \\
\hline 2 & $\mathrm{~B}, \mathrm{G}$, or $\mathrm{R}$ is VH or NIR is $\mathrm{M}$ & Building \\
\hline 3 & $\mathrm{~B}, \mathrm{G}$, or $\mathrm{R}$ is L or NIR is VH & Grass land \\
\hline 4 & $\mathrm{~B}, \mathrm{G}, \mathrm{R}$, or NIR is $\mathrm{H}$ & Bare Field \\
\hline
\end{tabular}

B, blue band; G, green band; R, Red band; NIR, near infrared band; VH, very high; $\mathrm{H}$, high; $\mathrm{M}$, middle; L, low

\subsubsection{Normalized difference vegetation index}

The Normalized Difference Vegetation Index (NDVI) has been utilized ever since the early satellite instruments for Earth observations, such as the National Aeronautics and Space 
Administration (NASA) Landsat satellite series and the National Oceanic and Atmospheric Administration (NOAA) Advanced Very High Resolution Radiometer (AVHRR) satellite series, which all acquired data in the red and near-infrared (NIR) spectral regions. The NDVI was often used to determine the spatial distribution of vegetation in these satellite images. Equation (1) represents the calculation of NDVI, where Red and NIR stand for the spectral measurements (as either DNs, radiances, or reflectance) acquired in the red and near-infrared regions, respectively.

$$
\mathrm{NDVI}=(\mathrm{NIR}-\mathrm{Red}) /(\mathrm{NIR}+\mathrm{Red})
$$

By utilizing the characteristics of NDVI in detecting the differential absorption properties of objects, this study produced the NDVI values for all of the training data sets while adopting fuzzy membership functions to represent the variance in each land use type (Fig. 5). In addition, the fuzzy rules for classification based on NDVI calculation are also summarized in Table 3 .

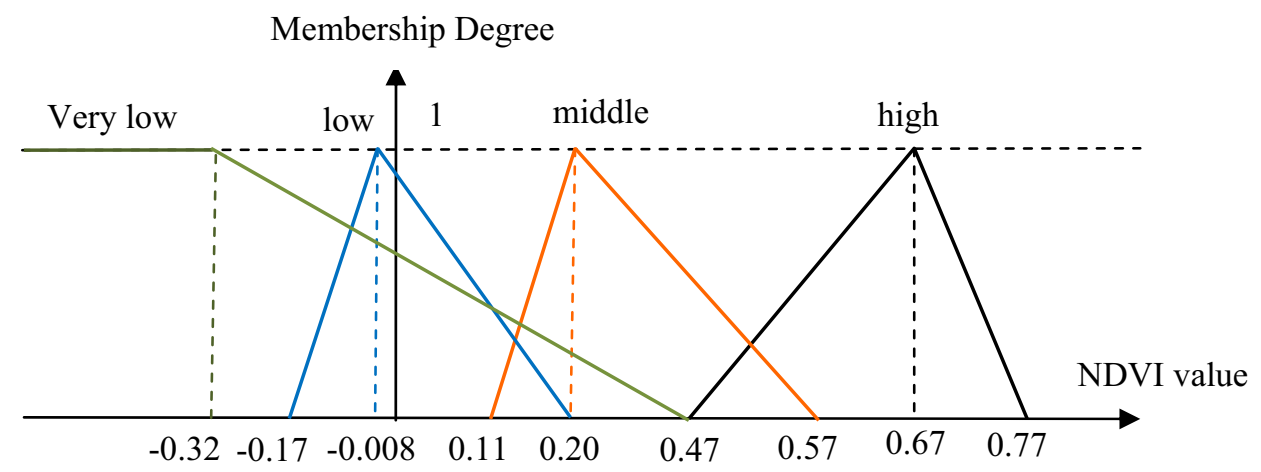

Fig. 5. The membership functions of NDVI values for various land covers.

Table 3. Fuzzy rules generated from NDVI values

\begin{tabular}{|c|c|c|c|}
\hline Rule no. & Fuzzy premises & Fuzzy consequences & NDVI value ranges \\
\hline 5 & NDVI is high & Grass Land & $0.47 \sim 0.77$ \\
\hline 6 & NDVI is middle & Bare Field & $0.11 \sim 0.57$ \\
\hline 7 & NDVI is low & Building & $-0.17 \sim 0.20$ \\
\hline 8 & NDVI is very low & River or Road & $-0.32 \sim 0.47$ \\
\hline
\end{tabular}

\subsubsection{Feature space}

In pattern recognition, a feature space is an abstract space in which each pattern sample is represented as a point in n-dimensional space. Its dimension is determined by the number of features used to describe the patterns. Similar samples are grouped together, allowing the use of density estimation for finding patterns. To outline the distributions of different land types, six 2-dimensional feature spaces were created for fuzzy synthetic analysis. Using Red and NIR bands as examples, Fig. 6 indicates the feature space where various land covers are gathered at specific locations owing to their differential absorption properties. High density spots represent the most general features for corresponding land usage types. Therefore, the 
fuzzy cluster method was used to separate these observed objects, and the fuzzy rules for classification were generated and listed in Table 4.
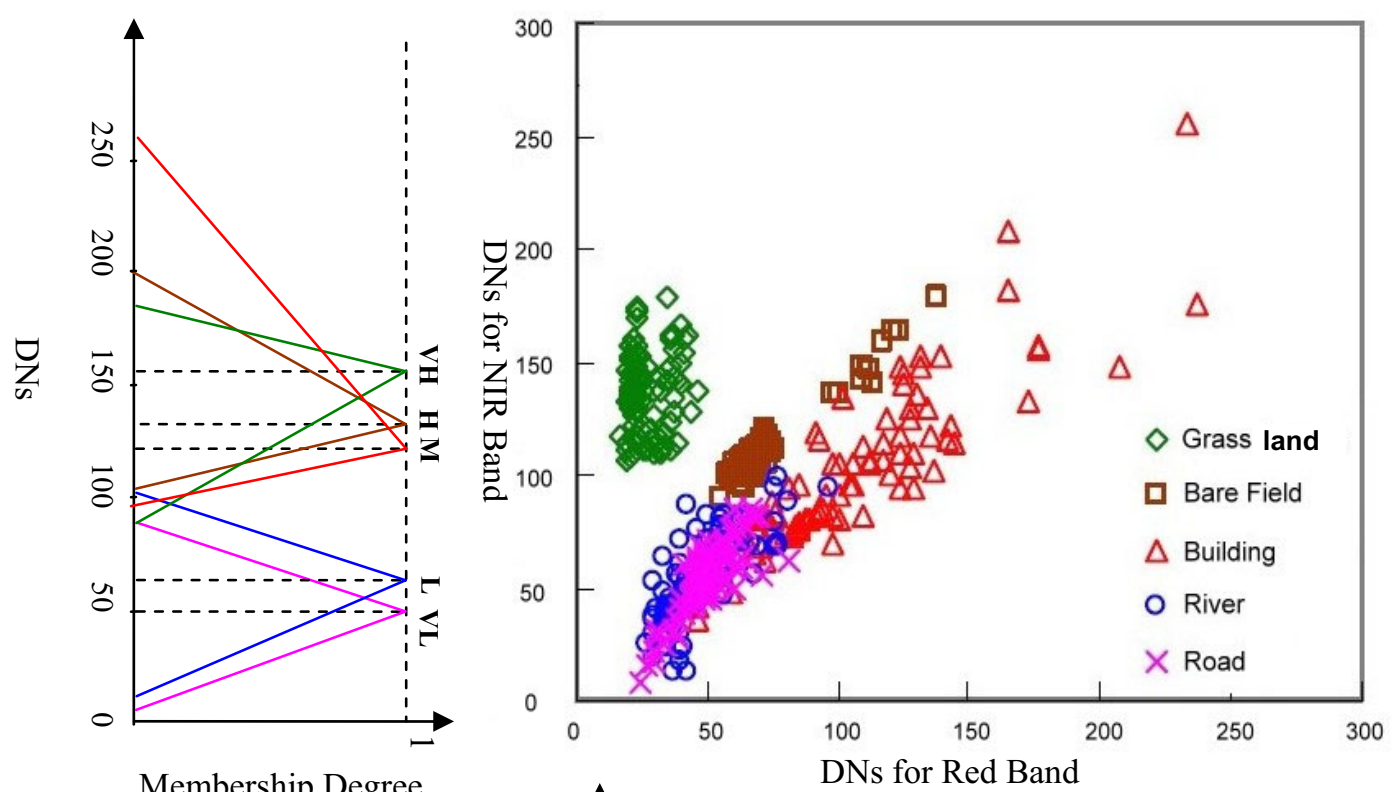

$$
\begin{aligned}
& \text { Membership Degree } \\
& \text { VL: very low } \\
& \text { L: low } \\
& \text { M: middle } \\
& \text { H: high } \\
& \text { VH: very high }
\end{aligned}
$$

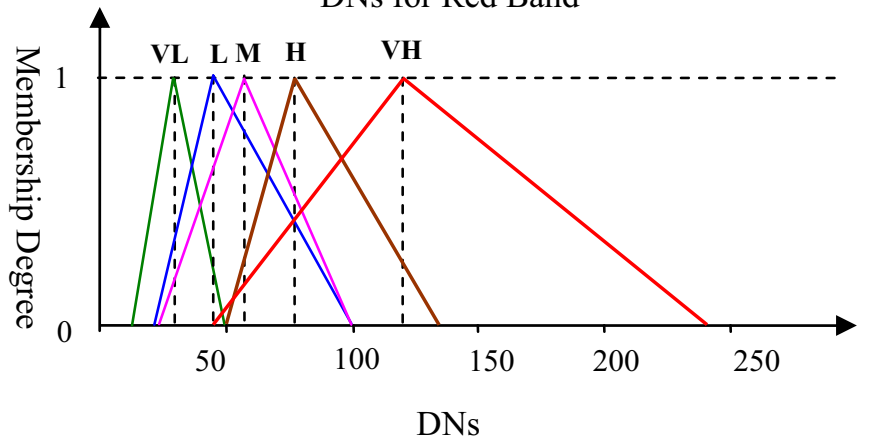

Fig. 6. The feature space composed of Red and a NIR bands

\subsubsection{Texture analysis}

Texture analysis is one of the fundamental aspects in image classification by which we can distinguish and recognize objects provided by information on surface patterns. For some objects with similar patterns, texture analysis provides some extra information on classifiers. The gray level co-occurrence matrix (GLCM) reveals certain properties about the spatial distribution of the gray levels in the texture image. To reveal the general texture features of different land covers, a total of 500 test sites were selected. After a series of calculations by 9 $\times 9$ co-occurrence matrices, texture features including dissimilarity, entropy, contract, homogeneity, correlation, and angular second moment [28] were obtained. They are shown in Fig. 7 in which the gray values associated with bands and LULC types can be characterized with respect to a set of ranges. In addition, the rules for classification derived from Fig. 7 are also shown in Table 5 from which six indices were collectively considered together, including 
contrast (CON), correlation (COR), homogeneity (Homo), entropy (ENT), dissimilarity (DIS), and angular second moment (ASM).

Table 4. Fuzzy rules derived from two-dimensional feature space

\begin{tabular}{|c|c|c|}
\hline Rule no. & If & Then \\
\hline 9 & NIR is VH and $\mathrm{R}$ is VL & Grass land \\
\hline 10 & NIR and $\mathrm{R}$ are $\mathrm{H}$ & Bare field \\
\hline 11 & NIR is $M$ and $R$ is VH & Building \\
\hline 12 & NIR and $R$ are $L$ & River \\
\hline 13 & NIR is VL and $R$ is $M$ & Road \\
\hline 14 & $\mathrm{G}$ and $\mathrm{B}$ are $\mathrm{VL}$ & Grass land \\
\hline 15 & $\mathrm{G}$ is $\mathrm{H}$ and $\mathrm{B}$ is $\mathrm{L}$ & Bare field \\
\hline 16 & $\mathrm{G}$ and $\mathrm{B}$ are $\mathrm{VH}$ & Building \\
\hline 17 & $\mathrm{G}$ and $\mathrm{B}$ are $\mathrm{M}$ & River \\
\hline 18 & $\mathrm{G}$ is $\mathrm{L}$ and $\mathrm{B}$ is $\mathrm{H}$ & Road \\
\hline 19 & $\mathrm{R}$ and $\mathrm{G}$ are $\mathrm{VL}$ & Grass land \\
\hline 20 & $\mathrm{R}$ and $\mathrm{G}$ are $\mathrm{H}$ & Bare field \\
\hline 21 & $\mathrm{R}$ and $\mathrm{G}$ is $\mathrm{VH}$ & Building \\
\hline 22 & $\mathrm{R}$ and $\mathrm{G}$ are $\mathrm{M}$ & River \\
\hline 23 & $\mathrm{R}$ and $\mathrm{G}$ are $\mathrm{L}$ & Road \\
\hline 24 & $\mathrm{R}$ and $\mathrm{B}$ are $\mathrm{VL}$ & Grass land \\
\hline 25 & $\mathrm{R}$ and $\mathrm{B}$ are $\mathrm{H}$ & Bare field \\
\hline 26 & $\mathrm{R}$ and $\mathrm{B}$ are $\mathrm{VH}$ & Building \\
\hline 27 & $\mathrm{R}$ and $\mathrm{B}$ are $\mathrm{L}$ & River \\
\hline 28 & $\mathrm{R}$ and $\mathrm{B}$ are $\mathrm{M}$ & Road \\
\hline 29 & NIR is VH and $\mathrm{G}$ is VL & Grass land \\
\hline 30 & NIR is VH and $\mathrm{G}$ is $\mathrm{H}$ & Bare field \\
\hline 31 & NIR is $M$ and $G$ is $H$ & Building \\
\hline 32 & NIR is $L$ and $G$ is $M$ & River \\
\hline 33 & NIR is VL and $G$ is $L$ & Road \\
\hline 34 & NIR is $\mathrm{VH}$ and $\mathrm{B}$ is VL & Grass land \\
\hline 35 & NIR is $\mathrm{H}$ and $\mathrm{B}$ is $\mathrm{L}$ & Bare field \\
\hline 36 & NIR is $\mathrm{M}$ and $\mathrm{B}$ is $\mathrm{VH}$ & Building \\
\hline 37 & NIR is $L$ and $B$ is $M$ & River \\
\hline 38 & NIR is VL and B is $\mathrm{H}$ & Road \\
\hline
\end{tabular}

B, blue band; G, green band; R, Red band; NIR, near infrared band; VH, very high;

$\mathrm{H}$, high; M, middle; L, low 

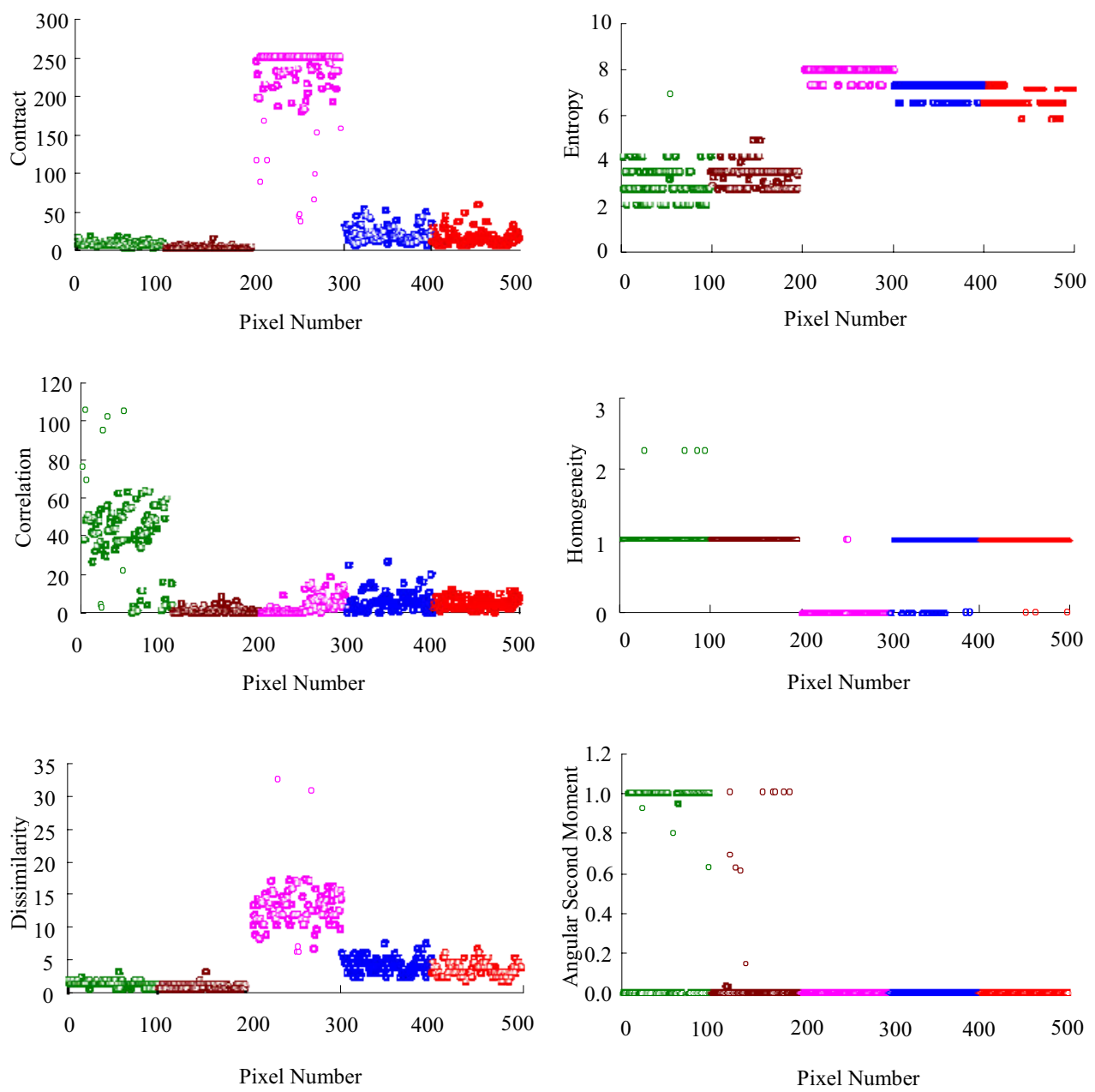

Legend :

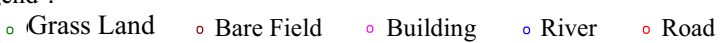

Fig. 7. The distributions of six texture features corresponding to various LULC types along an image scan line

\subsection{Fuzzy reasoning supported by artificial neural networks}

When the rules based on spectral and textural features inherent to satellite observations are extracted by mathematical tools, the fuzzy reasoning can be triggered by training data sets. We adopted the min-max fuzzy operator to integrate the outcomes resulting from different fuzzy rules: details of the procedure can be delineated in Fig. 8. To retrieve the inference implications, the weighted centroid defuzzification method was utilized to attribute the testing pixel to some special land cover. To increase the accuracy of classification, the ANN was integrated to optimize the weights used in defuzzification and tune the fuzzy membership functions described above simultaneously. At that point, the entire rule base can be determined simultaneously with phenomenological and theoretical implications. 
Table 5. Fuzzy rules generated from texture features

\begin{tabular}{|c|l|l|}
\hline Rule no. & \multicolumn{1}{|c|}{ If } & \multicolumn{1}{|c|}{ Then } \\
\hline 39 & $\begin{array}{l}1<\mathrm{CON}<28 \text { and } 0<\mathrm{COR}<105 \text { and } 1<\mathrm{DIS}<5 \text { and } \\
2<\mathrm{ENT}<7 \text { and } 1<\mathrm{HOM}<2 \text { and } 0<\mathrm{ASM}<1\end{array}$ & Grass land \\
\hline 40 & $\begin{array}{l}1<\mathrm{CON}<22 \text { and } 0<\mathrm{COR}<12 \text { and } 1<\mathrm{DIS}<5 \\
\text { and } 2.93<\mathrm{ENT}<6 \text { and } \mathrm{HOM}=1 \text { and } 0<\mathrm{ASM}<1\end{array}$ & Bare field \\
\hline 41 & $\begin{array}{l}32.5<\mathrm{CON}<255 \text { and } 0<\mathrm{COR}<26 \text { and } 6<\mathrm{DIS}<29.625 \\
\text { and } 7<\mathrm{ENT}<8 \text { and } 0<\mathrm{HOM}<1 \text { and } \mathrm{ASM}=0\end{array}$ & Building \\
\hline 42 & $\begin{array}{l}8<\mathrm{CON}<79 \text { and } 0<\mathrm{COR}<37 \text { and } 3<\mathrm{DIS}<10 \\
\text { and } 6<\mathrm{ENT}<7 \text { and } 0<\mathrm{HOM}<1 \text { and } \mathrm{ASM}=0\end{array}$ & River \\
\hline 43 & $\begin{array}{l}5.75<\mathrm{CON}<86 \text { and } 0<\mathrm{COR}<17 \text { and } 2<\mathrm{DIS}<9 \\
\text { and }<\mathrm{ENT}<7 \text { and } 0<\mathrm{HOM}<1 \text { and } \mathrm{ASM}=0\end{array}$ & Road \\
\hline
\end{tabular}

DIS, dissimilarity; ENT, entropy, CON, contract; HOM, homogeneity; COR, correlation;

ASM, Angular second moment

\section{RESULTS AND DISCUSSION}

To test the accuracy of the proposed methodology, 600 test data sets associated with raster pixels for each individual LULC type were randomly sampled from satellite images. This implies that we determined the land use patterns for $6 \times 600$ locations by comparison with groundtruth information. The predicted verdict outcomes are summarized in Table 6 showing that about $85 \%$ average accuracy in LULC classification can be achieved. The results indicate that such a hybrid neural-fuzzy inference algorithm for data mining can successfully isolate the green vegetated ground cover from other classes. In contrast, the worst discernment occurs in the river category due to the distinctive characteristics of the rivers in Taiwan. As shown in Fig. 9, both green vegetation and bare field categories often exist in the river beds during the dry season owing to the non-homogeneous distribution of river flow, and such situations decrease the effectiveness of the proposed methodology. Nevertheless, the proposed FNN still reveal an excellent ability in land cover classification in our study. Fig. 10 provides evidence that the proposed FNN can easily differentiate bare field, grass land, and road categories at the airport whereas most of these are roughly classified as grass land using the maximum likelihood method. The reasons for the major assignment errors are probably due to insufficient groundtruth data points. As a result, the rule-based model can achieve a more detailed description of fragmental land cover classes as summarized in Table 7. 


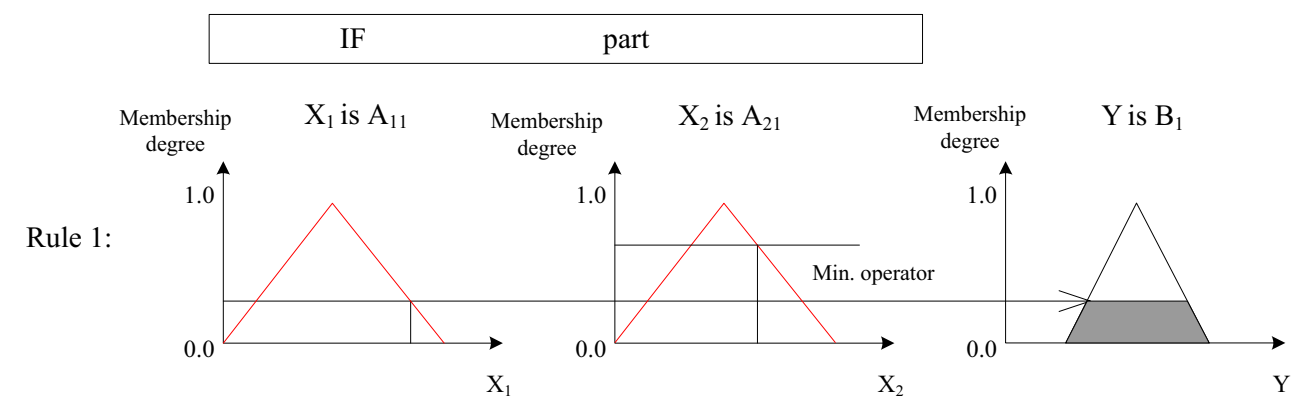

(a) Fuzzy inference for rule 1

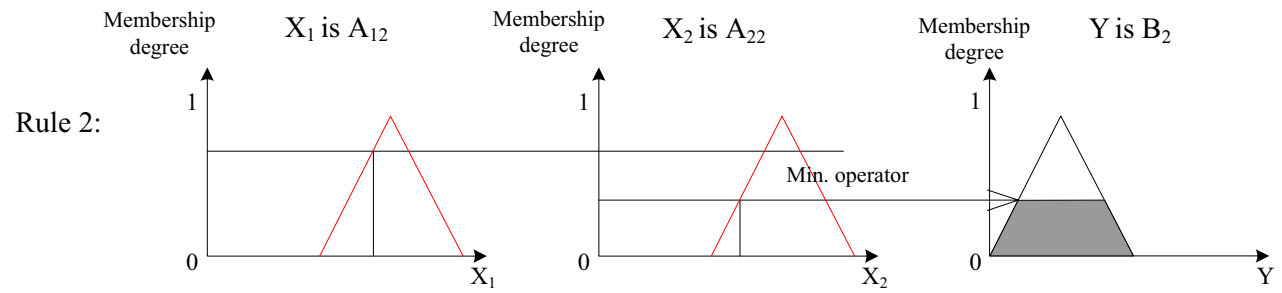

(b) Fuzzy inference for rule 2

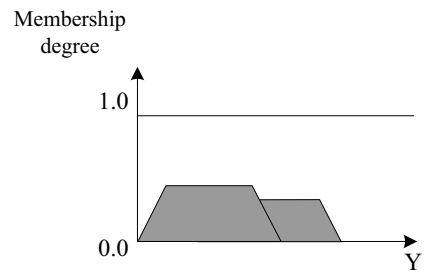

(c) Output fuzzy set by combining these two rules

Fig. 8. The flowchart of fuzzy reasoning

Table 6 . The results of land cover classification by neural-fuzzy classifier

\begin{tabular}{|c|c|c|c|c|c|c|}
\hline & & \multicolumn{5}{|c|}{ Actual condition } \\
\hline & & Grass land & Bare field & Building & River & Road \\
\hline \multirow{5}{*}{ 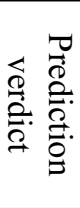 } & Grass land & 546 & 37 & 9 & 17 & 3 \\
\hline & Bare field & 32 & 510 & 25 & 45 & 25 \\
\hline & Building & 5 & 23 & 528 & 13 & 23 \\
\hline & River & 7 & 18 & 16 & 468 & 63 \\
\hline & Road & 10 & 15 & 22 & 57 & 486 \\
\hline \multicolumn{2}{|c|}{ Accuracy } & $91 \%$ & $85 \%$ & $88 \%$ & $71 \%$ & $81 \%$ \\
\hline \multicolumn{2}{|c|}{ Average of accuracy } & \multicolumn{5}{|c|}{$85 \%$} \\
\hline
\end{tabular}

Note: The total sample size is 600 for each LULC type. 

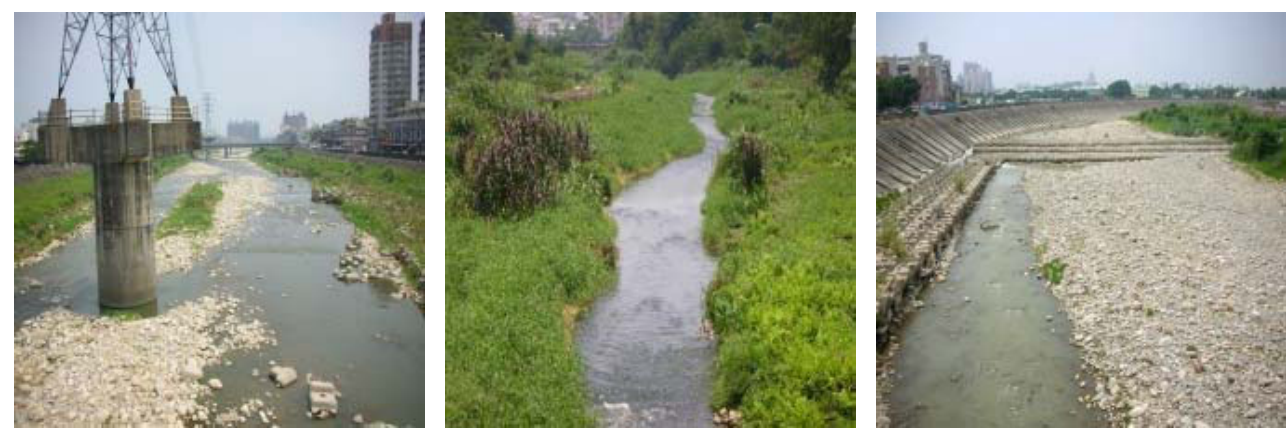

Fig. 9. Practical variations affecting the rivers in Taiwan

Table 7. Accuracy comparisons of different classification methods

\begin{tabular}{|l|c|c|c|c|}
\hline & ISODATA & $\begin{array}{c}\text { Maximum } \\
\text { Likelihood Method }\end{array}$ & $\begin{array}{c}\text { Texture } \\
\text { analysis }\end{array}$ & $\begin{array}{c}\text { Rule-based } \\
\text { method }\end{array}$ \\
\hline Grass land & 75.3 & 82.1 & 89.5 & 91 \\
\hline Bare field & 63.8 & 72.1 & 78.5 & 85 \\
\hline Building & 64.8 & 65.0 & 74.3 & 88 \\
\hline River & 30.0 & 40.0 & 52.2 & 78 \\
\hline Road & 30.9 & 51.1 & 55.8 & 81 \\
\hline average & 49.7 & 65.4 & 76.1 & 85 \\
\hline
\end{tabular}

Unit: percentage (\%)

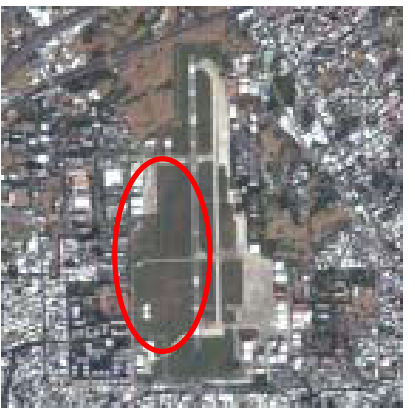

(A) Original image

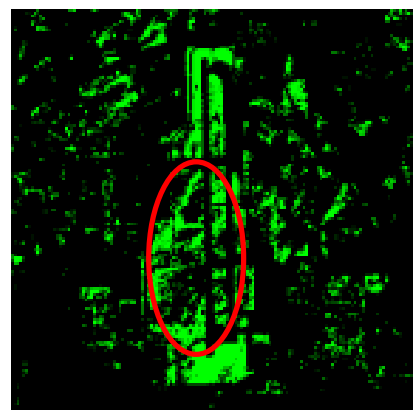

(B) Rule-based method

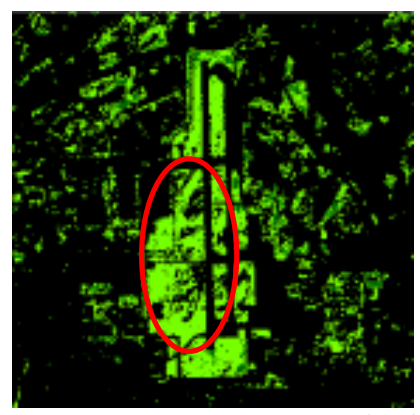

(C) Maximum likelihood method

Fig. 10.The classification results for an image using two different methods

On analyzing error sources from 2-dimensional feature space (Fig. 11), the results indicate that most of the erroneous judgments are distributed on the boundary between two different categories. Linear segmentation seems to be the likely factor contributing to these unexpected errors. To examine the relative importance of fuzzy rules in reasoning, the more important rules, as well as their weights, which were determined by the ANN module with selective training data sets, are summarized in Table 8 . They indicate that a 2-dimentional feature space composed of a green band; a NIR band, and the NDVI are the most important indicators for the green ground category (vegetation). Texture features play more important roles in segmenting building and river than other categories. Like the road category, feature space is also the main tool to identify the bare field in satellite images. With such efforts, the final results of land classification map for our study area - Taichung City - can be seen in Fig. 12. 

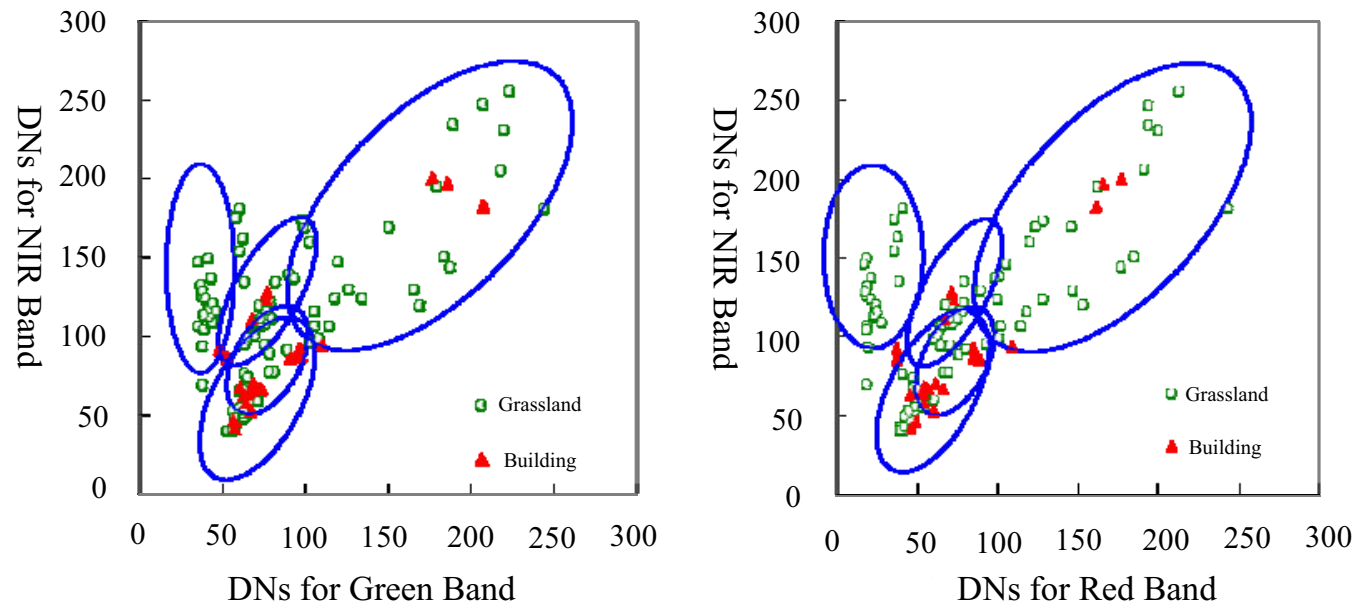

Fig. 11. The classification results in red-green feature space using different methods

Table 8 . The most important rules in land cover classification

\begin{tabular}{|c|c|c|}
\hline Land types & Rule number & Triggered strength \\
\hline \multirow{5}{*}{ Grass land } & 29 & 1.00 \\
\hline & 5 & 0.99 \\
\hline & 9 & 0.88 \\
\hline & 14 & 0.87 \\
\hline & 39 & 0.68 \\
\hline \multirow{5}{*}{ Bare field } & 30 & 1.00 \\
\hline & 10 & 0.98 \\
\hline & 15 & 0.98 \\
\hline & 20 & 0.91 \\
\hline & 25 & 0.84 \\
\hline \multirow{5}{*}{ Building } & 21 & 1.00 \\
\hline & 26 & 0.99 \\
\hline & 41 & 0.99 \\
\hline & 2 & 0.85 \\
\hline & 36 & 0.83 \\
\hline \multirow{5}{*}{ River } & 9 & 0.99 \\
\hline & 37 & 0.95 \\
\hline & 1 & 0.94 \\
\hline & 42 & 0.85 \\
\hline & 8 & 0.70 \\
\hline \multirow{5}{*}{ Road } & 38 & 0.97 \\
\hline & 23 & 0.90 \\
\hline & 33 & 0.82 \\
\hline & 13 & 0.78 \\
\hline & 8 & 0.70 \\
\hline
\end{tabular}




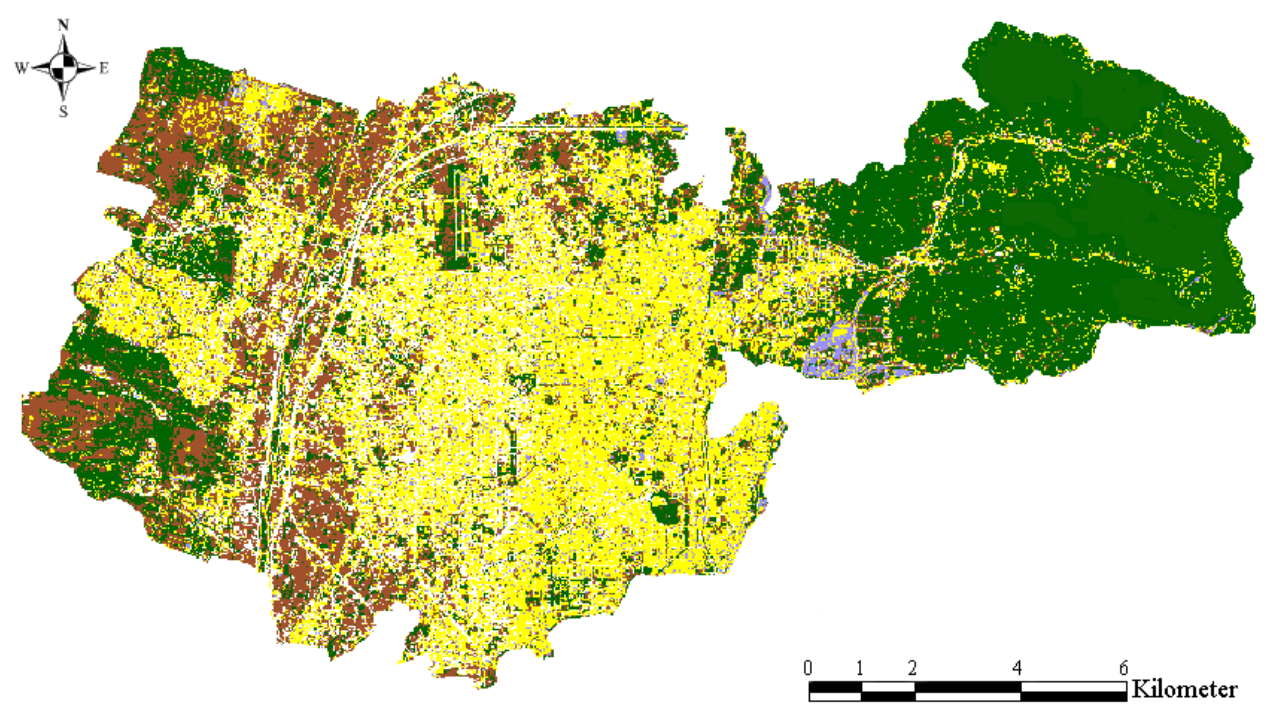

Legend:

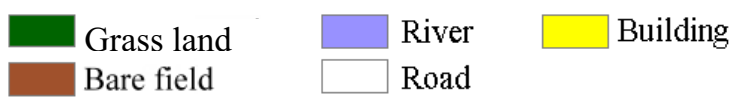

Fig. 12. Land classification map for September 2005 of our study area - Taichung City

Within this study, the ability to reliably separate a few LULC (4-5) classes via the use of the neural-fuzzy inference approach was demonstrated in a fast growing urban region. Taking advantage of the high spatial resolution satellite data provided by Formosat-2, the very high potential of this neural-fuzzy inference approach was amply shown since the rule base may be tuned flexibly to fit varying types of terrain. Further, such a method would not be limited by the types of sensors (e.g. bandwidth) onboard the satellite, the location of cities, and the acquired date because only B, R, G, and NIR images are needed. In other words, this data mining method is applicable for any type of sensor that is able to collect R, B, G, and NIR images, such as MODIS and Landsat. A probable limitation of using broad spectral bands (e.g., with Formosat-2) for categorical separation is the larger number of groundtruth data points needed to support the classification via the use of our neural-fuzzy inference approach. Yet more LULC types may be included since the rule base can be restructured to adapt such needs. To achieve this goal, however, more groundtruth data points may be required for more elaborate LULC studies.

\section{CONCLUSIONS}

This paper presents a comprehensive neural-fuzzy inference algorithm to integrate a relevant rule base for LULC classification based primarily on Formosat-2 satellite NDVI data. By embracing both the spectral and textural features, the derived fuzzy-neural rule base optimally incorporated the comparative advantages of each rule via a data mining process. The proposed FNN algorithm revealed its potential in dealing with fragmental LULC classification in a highly developed city in central Taiwan. Unlike black-box models, it is believed that this FNN model may be able to present the synergistic ability of integration, robustness, and flexibility with the aid of classification rules. With such advancement, we would be able to visually examine the response and tune or revise the rules in the LULC classification process 
interactively. However, much more validation work and analytical results will be required to demonstrate unequivocally that this procedure can perform better than others, making applications more practical and accurate in the future.

\section{Acknowledgments}

The authors express their deep gratitude to the National Science Council of Taiwan for financial support (NSC 95-2622-E-324-001-CC3).

\section{References}

[1] X. Chen, T. A. Warner, and D. J. Campagna, "Integrating visible, near-infrared and short-wave infrared hyperspectral and multispectral thermal imagery for geological mapping at Cuprite, Nevada," Rem. Sens. Environ. 110, 344-356 (2007). [doi: 10.1016/j.rse.2007.03.015]

[2] S. Myeong, D. J. Nowak, and M. J. Duggin, "A temporal analysis of urban forest carbon storage using remote sensing," Rem. Sens. Environ. 101, 277-282 (2006). [doi: 10.1016/j.rse.2005.12.001]

[3] Momeni, M. and M. R. Saradjian, "Evaluating NDVI-based emissivities of MODIS bands 31 and 32 using emissivities derived by Day/Night LST algorithm," Rem. Sens. Environ., 106(2), 190-198 (2007). [doi: 10.1016/j.rse.2006.08.005]

[4] Y. Qu, J. Wang, H. Wan, X. Li, and G. Zhou, "A Bayesian network algorithm for retrieving the characterization of land surface vegetation," Rem. Sens. Environ. 112, 613-622 (2008). [doi: 10.1016/j.rse.2007.03.031]

[5] O. Hagner, and H. Reese, "A method for calibrated maximum likelihood classification of forest types," Rem. Sens. Environ. 110, 438-444 (2007). [doi: 10.1016/j.rse.2006.08.017]

[6] D. J. Hayes, W. B. Cohen, S. A. Sader, and D. E. Irwin, "Estimating proportional change in forest cover as a continuous variable from multi-year MODIS data," Rem. Sens. Environ. 112, 735-749 (2008). [doi: 10.1016/j.rse.2007.06.003]

[7] S. Martinuzzi, W. A. Gould, and O. M. R. Gonzalez, "Land development, land use, and urban sprawl in Puerto Rico integrating remote sensing and population census data," Landscape Urban Plan. 79, 288-297(2007). [doi: 10.1016/j.landurbplan.2006.02.014]

[8] Q. Wu, H. Q. Li, R. S. Wang, J. Paulussen, Y. Hec, M. Wang, B. H. Wang, and Z. Wang, "Monitoring and predicting land use change in Beijing using remote sensing and GIS," Landscape Urban Plan. 78, 322-333 (2006). [doi: 10.1016/j.landurbplan.2005.10.002]

[9] M. Jung, K. Henkel, M. Herold, and G. Churkina, "Exploiting synergies of global land cover products for carbon cycle modeling," Rem. Sens. Environ., 101, 534-553 (2006). [doi: 10.1016/j.rse.2006.01.020]

[10] U. Heiden, K. Segl, S. Roessner, and H. Kaufmann, "Determination of robust spectral features for identification of urban surface materials in hyperspectral remote sensing data," Rem. Sens. Environ. 111, 537-552 (2007). [doi: 10.1016/j.rse.2007.04.008]

[11]J. Zhang, and Y. Zhang, "Remote sensing research issues of the National Land Use Change Program of China," J Photogramm. Rem. Sens. 62, 461-472 (2007). [doi: 10.1016/j.isprsjprs.2007.07.002]

[12] T. G. Vagen, "Remote sensing of complex land use change trajectories-a case study from the highlands of Madagascar," Agr. Ecosyst. Environ. 115, 219-228 (2006). [doi: 10.1016/j.agee.2006.01.007] 
[13] A. A. Gitelson, J. F. Schalles, and C. M. Hladik, "Remote chlorophyll-a retrieval in turbid, productive estuaries: Chesapeake Bay case study," Rem. Sens. Environ. 109, 464-472 (2007). [doi: 10.1016/j.rse.2007.01.016]

[14]F. J. Lozano, S. Suárez-Seoane, M. Kelly, and E. Luis, "A multi-scale approach for modeling fire occurrence probability using satellite data and classification trees: A case study in a mountainous Mediterranean region," Rem. Sens. Environ. 112, 708719 (2008). [doi: 10.1016/j.rse.2007.06.006]

[15] U. Amato, A. Antoniadis, V. Cuomo, L. Cutillo, M. Franzese, L. Murino, and C. Serio, "Statistical cloud detection from SEVIRI multispectral images," Rem. Sens. Environ. 112, 750-766 (2008). [doi: 10.1016/j.rse.2007.06.004]

[16] J. Ju, S. Gopal, and E. D. Kolaczyk, "On the choice of spatial and categorical scale in remote sensing land cover classification," Rem. Sens. Environ. 96, 62-77(2005). [doi: 10.1016/j.rse.2005.01.016]

[17] A. M. Filippi, and J. R. Jensen, "Fuzzy learning vector quantization for hyperspectral coastal vegetation classification," Rem. Sens. Environ. 100, 512-530 (2006). [doi: 10.1016/j.rse.2005.11.007]

[18] R. Tapia, A. Stein, and W. Bijker, "Optimization of sampling schemes for vegetation mapping using fuzzy classification," Rem. Sens. Environ. 99, 425-433(2005). [doi: 10.1016/j.rse.2005.09.013]

[19]F. J. Triepke, C. K. Brewer, D. M. Leavell, and S. J. Novak, "Mapping forest alliances and associations using fuzzy systems and nearest neighbor classifiers," Rem. Sens. Environ. 112, 1037-1050 (2008). [doi:10.1016/j.rse.2007.07.014]

[20] J. Verhoeye and R. De Wulf, "Land cover mapping at sub-pixel scales using linear optimization techniques," Rem. Sens. Environ. 79, 96-104 (2002). [doi: 10.1016/ S0034- 257(01)00242-5]

[21] L. A. Zadeh, "Fuzzy sets," Inform. Control. 8(3), 338-353(1965). [doi: 10.1016/ S0019-9958(65)90241-X]

[22] J. Favela and J. Torres, "A two-step approach to satellite image classification using fuzzy neural networks and the ID3 learning algorithm," Expert Syst. Appl. 14(1-2), 211-218 (1998). [doi: 10.1016/S0957-4174(97)00071-7]

[23] H. Iyatomi and M. Hagiwara, "Scenery image recognition and interpretation using fuzzy inference neural networks," Pattern Recogn. 35(8), 1793-1806 (2002). [doi: 10.1016/S0031-3203(01)00171-6]

[24] A. Quteishat and C. P. Lim, "A modified fuzzy min-max neural network with rule extraction and its application to fault detection and classification," Appl. Soft Comput. 8(2), 985-995 (2008). [doi: 10.1016/j.asoc.2007.07.013]

[25] Y. C. Hu, R. S. Chen, and G. H. Tzeng, "Finding fuzzy classification rules using data mining techniques," Pattern Recogn. Lett. 24(1-3), 509-519 (2003). [doi: 10.1016/ S0167-8655(02)00273-8]

[26] T. P. Hong, T. T. Wang, and S. L. Wang, "Mining fuzzy $b$-certain and $b$-possible rules from quantitative data based on the variable precision rough-set model," Expert Syst. Appl. 32(1), 223-232 (2007). [doi: 10.1016/j.eswa.2005.11.009]

[27] C. Smith and N. Brown, Erdas Field Guide, 4th ed., Erdas Inc. (1997)

[28] R. M. Haralick, "Statistical and Structural Approaches to Texture," in Proceedings of the IEEE, 67(5), 786-804 (1979). 